Tropical Journal of Pharmaceutical Research March 2021; 20 (3): 559-565

ISSN: $1596-5996$ (print); 1596-9827 (electronic)

(C) Pharmacotherapy Group, Faculty of Pharmacy, University of Benin, Benin City, 300001 Nigeria.

Available online at http://www.tjpr.org

Original Research Article

http://dx.doi.org/10.4314/tjpr.v20i3.17

\title{
MiR-489 serves as a tumor inhibitor in pituitary prolactinoma targeting p21-activated kinase 3
}

\author{
Lie Zhang ${ }^{1}$, Shuchuan Miaoㄹ, Zhongxin Yang1, Zongxi Li ${ }^{1}$, Qun Zheng ${ }^{2 *}$ \\ ${ }^{1}$ Department of Neurosurgery, The First Affiliated Hospital of Chengdu Medical College, 610500, ${ }^{2}$ Department of Health \\ Management Physical Examination Center, Chengdu Fifth People's Hospital, Chengdu City, Sichuan Province 611130, China \\ *For correspondence: Email: zhengqun1207@163.com; Tel: +86-028-82726515
}

Sent for review: 6 January 2021

Revised accepted: 6 March 2021

\begin{abstract}
Purpose: To evaluate the effect of microRNA-489 (miR-489) on pituitary prolactinoma and its mechanisms of action.

Methods: MMQ and $G H 3$ cells were transfected with miR-489, cell viability assessed with cell counting kit-8 (CCK-8), and clone spots was evaluated by colony formation assay. Transwell assay was applied to measure cell migration and invasion while TargetScan was employed to the presumed targets of miR-489, followed by luciferase reporter assays. was MiR-489 and p21-activated kinase 3 (PAK3) gene expression were determined by quantitative reverse transcription-polymerase chain reaction (qRT-PCR. Protein levels of PAK3 were measured using western blots.

Results: Transfection significantly increased miRNA-489 levels $(p<0.01)$. Cell viability, number of clone spots, as well as cell migration and invasion diminished in MMQ and GH3 cells following miR-489 transfection when compared to miR-NC mimic group $(p<0.01)$. The presumed binding site of miRNA489 was located in 3'-untranslated region (UTR) of PAK3, and miR-489 transfection repressed luciferase activity with the wild-type 3'-UTR $(p<0.05)$. In addition, miR-489 decreased PAK3 levels in $M M Q$ and GH3 cells. Knockdown of PAK3 significantly suppressed cell viability, clone formation ability, as well as cell migration and invasion when compared to negative control $(p<0.01)$.

Conclusion: MiR-489 overexpression suppresses pituitary prolactinoma by targeting PAK3, thus providing a potential therapeutic strategy for the management of pituitary prolactinoma.
\end{abstract}

Keywords: Pituitary prolactinoma, MicroRNAs, P21-activated kinase 3

\begin{abstract}
This is an Open Access article that uses a fund-ing model which does not charge readers or their institutions for access and distributed under the terms of the Creative Commons Attribution License (http://creativecommons.org/licenses/by/4.0) and the Budapest Open Access Initiative (http://www.budapestopenaccessinitiative.org/read), which permit unrestricted use, distribution, and reproduction in any medium, provided the original work is properly credited.

Tropical Journal of Pharmaceutical Research is indexed by Science Citation Index (SciSearch), Scopus, International Pharmaceutical Abstract, Chemical Abstracts, Embase, Index Copernicus, EBSCO, African Index Medicus, JournalSeek, Journal Citation Reports/Science Edition, Directory of Open Access Journals (DOAJ), African Journal Online, Bioline International, Open-J-Gate and Pharmacy Abstracts
\end{abstract}

\section{INTRODUCTION}

Pituitary prolactinoma is the most common pituitary adenoma, which accounts for about $40 \%$ of all pituitary tumors [1]. They commonly occur in women aged 20-50 years old [2] and were long considered as leading causes of hypogonadism and infertility [1]. Some advances has been made in the treatment of pituitary prolactinoma, but common side effects after administration of bromocriptine and cabergoline include nausea, vomiting, nasal stuffiness, headache, and drowsiness [3]. Surgery can lower prolactin levels in most patients with small pituitary tumors, but many pituitary tumors recur within 5 years [3]. Therefore, novel therapies for pituitary prolactinoma need to be developed. 
MicroRNAs (miRNAs) are small, non-coding RNAs that regulate gene expression in a variety of biological properties including tumorigenesis, proliferation, and cell differentiation [4,5]. Compelling lines of evidences have revealed that miRNAs played different roles in carcinogenesis [6]. MiR-21 is overexpressed in many cancers such as glioma, breast cancer, and hepatocellular carcinoma [7], and miR-200c, miR-34a, and miR-107 induce or promote tumors progression [8]. By contrast, miR-489 is a tumor suppressor gene that inhibits the progression of squamous cell carcinoma [9], and miR-489 suppresses human gastric cancer [10]. In addition, miR381, miR-300, and miR-655 were considered as tumor suppressors in $\mathrm{CH} 3$ and MMQ cell lines [8]. However, the effect of miR489 on pituitary prolactinoma remains unknown and warrants further studies.

PAK3 (p21-activated kinase 3 ) belongs to the serine/threonine p21-activated kinase family, and its overexpression has been associated with both oncogenesis and cell migration [11]. Unfortunately, little is known regarding the effect of PAK3 on pituitary prolactinoma. Herein, the role and potential mechanism of miR-489 in pituitary prolactinoma were investigated in $\mathrm{MMQ}$ and $\mathrm{GH} 3$ cell lines.

\section{EXPERIMENTAL}

\section{Cell culture}

Prolactinoma $\mathrm{MMQ}$ and $\mathrm{GH} 3$ cell lines were bought from Shanghai Cell Bank, Chinese Academy of Sciences, and cultured in $\mathrm{F}-12 \mathrm{~K}$ culture medium (Gibco, USA), containing $10 \%$ fetal bovine serum (FBS, Thermo Fisher Scientific) and $100 \mathrm{U} / \mathrm{mL}$ penicillin/streptomycin (Gibco). HEK293 cells (Thermo Fisher Scientific) were grown in Dulbecco's modified Eagle's medium (Gibco) containing $10 \%$ FBS at $37{ }^{\circ} \mathrm{C}$ in $5 \% \mathrm{CO}_{2}$.

\section{Cell transfection and luciferase report assays}

The miR-489 mimic was employed to overexpress miR-489, and the negative control mimic (NC-mimic) was used as a control. An miR-489 inhibitor was used to inhibit miR-489 and NC-inhibitor was used as a control for miR489 inhibitor. MMQ, GH3, and HEK293 cells were transfected with miR-489 mimic, NC-mimic, miR-489 inhibitor, and NC-inhibitor by use of Lipofectamine 2000 (Invitrogen, USA).

To knockdown PAK3, cells were transfected with small interfering RNA (66 nmol/L) oligonucleotides against PAK3 (PAK3
SIGENOME SMART pool; Dharmacon, USA) using Lipofectamine 2000 (Invitrogen). At $48 \mathrm{~h}$ after transfection, the cells were harvested for further experiments.

The presumed target genes and the conserved miRNA-binding site seed regions were obtained by TargetScan (release 7.2, http://www. targetscan.org/). Then, pmirGLO vector (Riobio, Guangzhou, China) was utilized to clone the 3'UTR of PAK3 containing miR-489 binding sites. The miRNA seed sequence of PAK3 were mutated, and the construct was then cotransfected with luciferase reporter constructs and wild-type (WT) as well as mutant (Mut) corresponding miRNAs. At $48 \mathrm{~h}$ after transfection, a dual-reporter luciferase assay system in a plate-reader (Plastic Surgery Laboratory, University of Pittsburgh, USA) was employed to determine luciferase activity.

\section{Cell viability and colony formation assay}

$\mathrm{MMQ}$ and $\mathrm{GH} 3$ cells $\left(1 \times 10^{4}\right.$ cells/well) were placed in a 48-well plate overnight. CCK-8 assays (Dojindo Laboratories, Japan) were employed to assess cell viability. After $30 \mathrm{~min}$, the absorbance was obtained with a microplate reader (Gen5 ${ }^{\mathrm{TM}}$ ELISA BioTek Software, USA).

After $48 \mathrm{~h}$ transfection with miR-489 mimics or knockdown of PAK3, cells $\left(5 \times 10^{3}\right)$ were placed in a $100-\mathrm{mm}$ plate with dish filling with $3 \mathrm{ml}$ sterile water and cultured for 14 days, followed by staining with crystal violet staining solution (Beyotime Biotechnology, China) based on the manufacturer's instructions. A ZEISS Axiovert 200 microscope (Oberkochen, Germany) was used to image the cells, and colonies were counted using PhotoShop CS6 (Adobe, USA).

\section{Transwell assay}

For invasion assays, MMQ and GH3 cells $(3 \times$ $10^{4}$ ) were cultured for $48 \mathrm{~h}$ and transferred to Matrigel-coated Transwell chambers (Corning, NY, USA) for $48 \mathrm{~h}$. The cells were fixed with $4 \%$ paraformaldehyde followed by hematoxylin staining. A microscope (Olympus, Japan) was utilized, and invasion ability is expressed as average number of invasive cells.

For migration assays, MMQ and $\mathrm{GH} 3$ cells $(3 \times$ $10^{4}$ ) were placed in the upper chamber and migrated in the vertical direction into the lower chamber through the membrane pores. Next, the membrane was fixed using $4 \%$ paraformaldehyde, and non-migrated cells were discarded. 
Table 1: Primer pairs for amplification

\begin{tabular}{lll}
\hline Gene & Primer & \\
\hline miR-489 & 5'-ACACTCCAGCTGGGGTGACATCACAT & 5'-TGGTGTCGTGGAGTCG-3' (reverse) \\
PAK3 & $\begin{array}{l}\text { A-3' (forward) } \\
\text { 5'-TCACTCCTGAGCAAAGTAAACG-3' }\end{array}$ & $\begin{array}{l}\text { 5'-TCCCAGAGACCAGATATCAACTT-3' } \\
\text { (reverse) }\end{array}$ \\
$\begin{array}{l}\text { (forward) } \\
\text { GAPDH }\end{array}$ & $\begin{array}{l}\text { 5'-CAAGCTCATTTCCTG GTATGAC-3' } \\
\text { (forward) }\end{array}$ & $\begin{array}{l}\text { 5'-CAGTGAGGGTCTCTCTCTTCCT-3' } \\
\text { (reverse) }\end{array}$ \\
& $\begin{array}{l}\text { 5'-CTCGCTTCGGCAGCACATATACTA-3' } \\
\text { (forward) }\end{array}$ & $\begin{array}{l}\text { 5'-ACGAATTTGCGTGTCATCCTTGCG-3' } \\
\text { (reverse) }\end{array}$ \\
\hline
\end{tabular}

Migrated cells were stained by hematoxylin and counted with a microscope (Olympus, Japan).

\section{Reverse transcription and quantitative polymerase chain reaction}

TRIzol (Invitrogen) was utilized to extract total cellular RNA from MMQ and GH3 cells. SuperScript@ III cDNA Synthesis Kits (Invitrogen) were used for cDNA synthesis. Next, RT-qPCR was performed with the QuantiTect SYBR Green PCR kit (QiaGen) and 7500 fast real-time PCR system. The PCR program was 95 ${ }^{\circ} \mathrm{C}$ for $10 \mathrm{~min}, 40$ cycles of denaturation at $95{ }^{\circ} \mathrm{C}$ for $15 \mathrm{~s}$, and annealing/extension at $63{ }^{\circ} \mathrm{C}$ for $1 \mathrm{~min}$. Glyceraldehyde 3-phosphate dehydrogenase (GAPDH) was utilized as an endogenous control. The $2^{-\triangle \triangle C T}$ method [12] was utilized to quantify relative miR-489 expression normalized to U6 snRNA levels. The primer pairs used for amplification are shown in Table 1.

\section{Western blot}

Whole proteins were prepared from $\mathrm{MMQ}$ and GH3 cells using lysis buffer (Beyotime) on ice, transferred to nitrocellulose membranes (BioRad, USA), and blocked in 5\% non-fat milk in Tris-buffered saline buffer. Then the membranes were incubated with primary antibodies against PAK3 (1:1000 dilution, Abcam, UK) and GAPDH (1:1000 dilution, Abcam) overnight at room temperature, followed by the incubation with horseradish peroxidase-conjugated anti-rabbit or anti-mouse IgG (Promega, USA). Next, blots were visualized using enhanced chemiluminescence.

\section{Statistical analysis}

SPSS software (version 17.0, SPSS Inc, Chicago, USA) was utilized for all statistical analyses. The experimental data are expressed as mean \pm standard deviation. One-way analysis of variance was used with Tukey's multiple comparison tests for multiple groups. A value of $p<0.05$ was considered as statistical significance.

\section{RESULTS}

\section{MiR-489 inhibits proliferation of prolactinoma cell lines}

As shown in Figure $1 \mathrm{~A}$, transfection with miRNA489 mimic significantly increased miRNA-489 levels compared to the miR-NC mimic group $(p<$ $0.01)$. Cell viability was also inhibited after miRNA-489 mimic transfection $(p<0.01)$ (Figure $1 \mathrm{~B})$. Subsequently, the cell clone ability was determined with clone formation assays, and the number of clone spots decreased following miR489 application in MMQ and GH3 cells compared to those in the miR-NC mimic group $(p<0.01)$ (Figure $1 \mathrm{C}$ ). Collectively, these findings indicate that miR-489 inhibited proliferation in both prolactinoma cell lines.

A

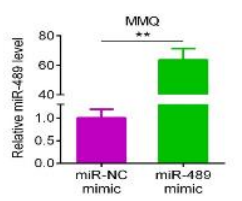

B
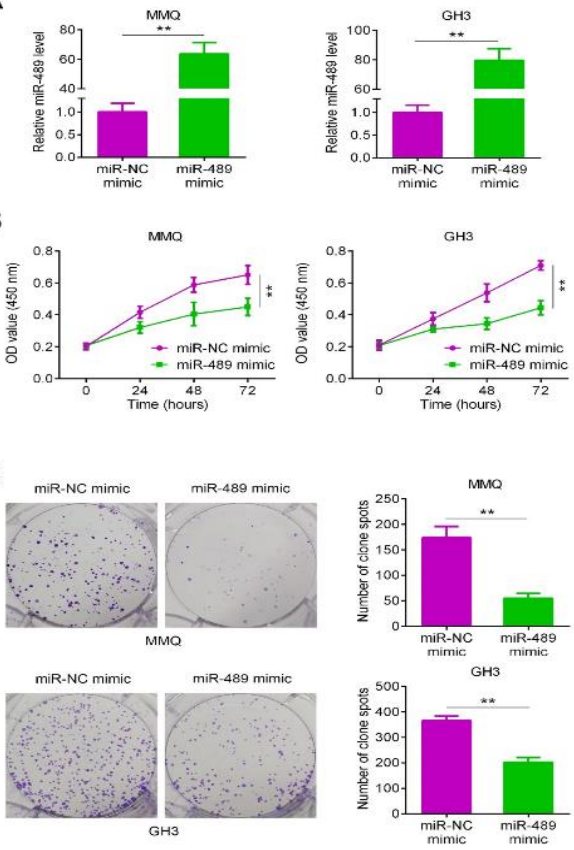

Figure 1: MiR-489 decreased proliferation in both the $\mathrm{MMQ}$ and $\mathrm{GH} 3$ cell lines. $\mathrm{A}$, mRNA expression of miR489. B, Cell viability determined by CCK-8 assays. C, Clone formation assays; ${ }^{* *} p<0.01$, compared to the miR-NC mimic 
MiR-489 inhibits prolactinoma cell line migration and invasion

For migration assays, miR-489 transfection visibly inhibited the number of migrated cells in both the MMQ and $\mathrm{GH} 3$ cell lines compared to the miR-NC mimic $(p<0.01)$ (Figure 2). In addition, there were significantly fewer invasive cells in the MMQ and $\mathrm{GH} 3$ cell lines transfected with miR-489 compared to the miR-NC mimic ( $p$ $<0.01$ ) (Figure 2). The results demonstrate miR489 suppressed cell migration and invasion in both prolactinoma cell lines.
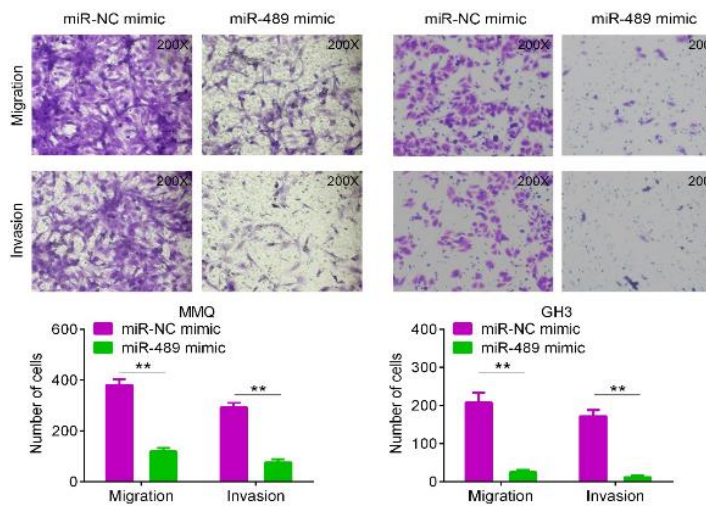

Figure 2: MiR-489 suppressed cell migration and invasion in $\mathrm{MMQ}$ and $\mathrm{GH} 3$ cell lines; ${ }^{* *} p<0.01$, compared to the miR-NC mimic

\section{MiR-489 directly targets PAK3}

Figure $3 \mathrm{~A}$ shows the presumed binding site of miRNA-489 located in the 3'-UTR, and the complementary sequences between miR-489 and PAK3 were CUACAGU and GAUGUCA. Reporter assays revealed miR-489 transfection distinctly suppressed the luciferase activity of the PAK WT 3'-UTR construct compared to the miRNC mimic $(p<0.05)$ (Figure 3 B), but no significant difference was observed in the luciferase activity of the construct with the PAK mutant 3'-UTR.

To evaluate the effects of miR-489 overexpression and knockdown on PAK3, miR489 inhibition and overexpression were performed in $\mathrm{GH} 3$ and $\mathrm{MMQ}$ cells. Figure $3 \mathrm{C}$ displayed the miR-489 mimic significantly downregulated PAK3 expression in MMQ cells $(p$ $<0.01)$ and $\mathrm{GH} 3(p<0.05)$ compared to the miR-NC, while there was no significant difference between miR-NC inhibitor and miR-489 inhibitor treatments. PAK3 protein levels were also significantly downregulated after miR-489 mimic treatment $(p<0.01)$ (Figure $3 \mathrm{D})$. However, the miR-489 inhibitor upregulated protein levels of PAK3 compared to the miR-NC inhibitor $(p<$
0.01 ) (Figure $3 \mathrm{D}$ ). These findings indicate that miR-489 directly targeted PAK3 during the process of translation.

A
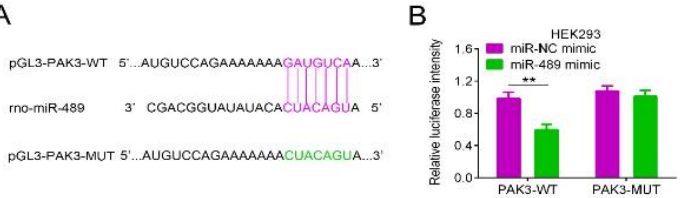

C
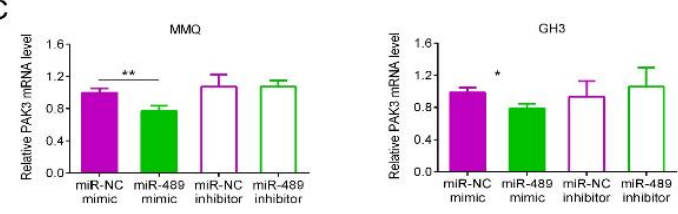

D
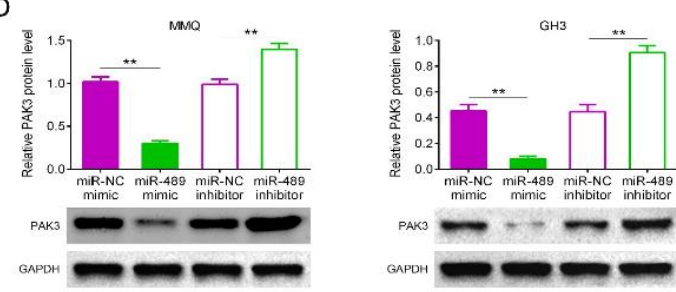

Figure 3: MiR-489 directly targeted PAK3. A, The sequences of miR-489 and its putative binding site in the 3'-UTR of PAK3. B, Luciferase activity assays after miR-489 mimic transfection into HEK293 cells. C, PAK3 mRNA levels measured by RT-qPCR after miR489 knockdown and overexpression. D, PAK3 protein levels determined using western blot after miR-489 knockdown and overexpression; * $p<0.05$ compared to the miR-NC mimic; ${ }^{* *} p<0.01$ compared to the miRNC mimic or miR-NC inhibitor. PAK3, p21-activated kinase 3

\section{Knockdown of PAK3 inhibits prolactinoma cell line proliferation, migration, and invasion}

Next, cell proliferation, migration, and invasion were assessed following knockdown of PAK3 in $M M Q$ and $\mathrm{GH} 3$ cell lines to elucidate the effect of PAK3 on prolactinoma cells. Figure $4 \mathrm{~A}$ shows that PAK3 knockdown successfully downregulated PAK3 levels in MMQ and $\mathrm{GH} 3$ cells $(p<0.01)$. CCK-8 assays showed a significant reduction in cell viability after knockdown of PAK3 compared to the shNC group $(p<0.01)$ (Figure 4B). Clone formation ability was also significantly inhibited following PAK3 knockdown compared to the shNC group $(p<0.01)$ (Figure 4 C). The results from Transwell assays indicated that knockdown of PAK3 repressed cell migration and invasion in MMQ and GH3 cells compared to the shNC group $(p<0.01)$ (Figure 4 D). Overall, knockdown of PAK3 inhibited proliferation, migration, and invasion in both prolactinoma cell lines. 
A

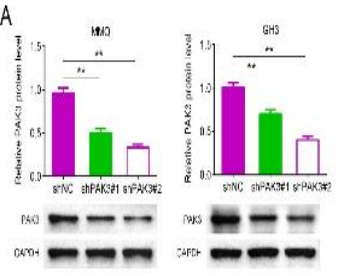

B

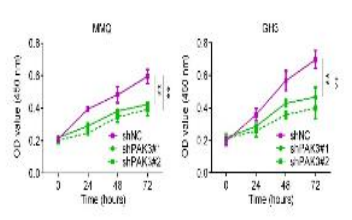

C

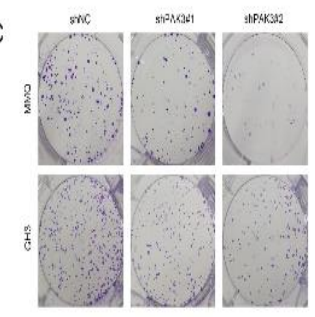

D

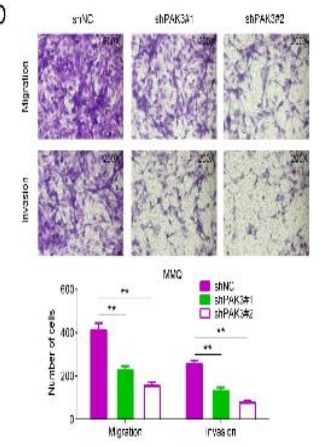

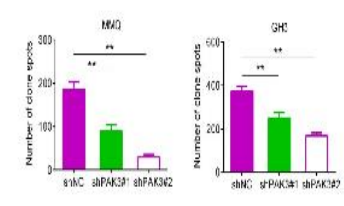

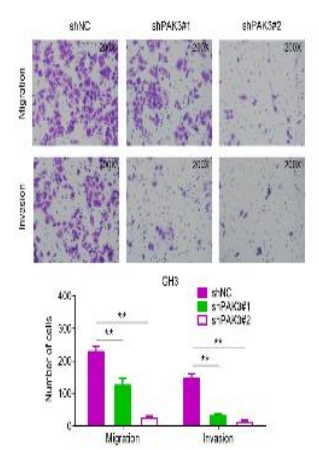

Figure 4: PAK3 knockdown repressed proliferation, migration, and invasion in $\mathrm{MMQ}$ and $\mathrm{GH} 3$ cell lines. $\mathrm{A}$, PAK3 protein levels determined using western blot. B, Cell viability measured using CCK-8 assay. C, Clone formation assays. D, Results of Transwell assays performed to evaluate the effect of PAK3 on cell migration and invasion; ${ }^{* *} p<0.01$ compared to the shNC. PAK3, p21-activated kinase 3

\section{DISCUSSION}

In clinical practice, aggressive prolactinomas still pose challenges for doctors, and abnormal miRNA expression is related to their invasive behavior [13]. In this study, miR-489 overexpression suppressed proliferation, clone formation, migration, and invasion in prolactinoma cell lines. Furthermore, miR-489 directly targeted the 3 '-UTR of PAK3. Knockdown of PAK3 repressed prolactinoma cell proliferation, migration, and invasion, suggesting miR-489 serves as tumor inhibitor in pituitary prolactinoma through targeting PAK3.

Compelling evidence identified key roles of microRNAs in modulating genes in various cancers [14,15]. Alderman and colleagues found that miR-15a inhibited melanoma proliferation and invasion through targeting cell division cycle

associated 4 and suggested that miR-15a might serve as novel microRNA-based treatment for melanoma [16]. Another group reported that miR143 suppressed cell migration and invasion in colorectal cancer through targeting metastasisassociated in colon cancer-1 [14]. A recent study revealed that miR-137 functioned as an invasive suppressor in prolactinomas by targeting microphthalmia-associated transcription factor and modulating the Wnt- $\beta$-catenin pathway [13]. In addition, miR-489 overexpression in mammary tumors altered progenitor cell populations and inhibited tumorigenesis by directly targeting human epidermal growth factor receptor-2 [17].

In glioma, loss of miR-489 induced the malignant phenotype, while miR-489 overexpression suppressed cell growth and promoted glioma cells apoptosis directly targeting the Spindlin 1mediated phosphatidylinositol 3kinase/serine/threonine kinase pathway [18]. Besides, miR-489 suppressed hypopharyngeal squamous cell carcinoma by targeting tyrosineprotein phosphatase non-receptor type 11 [9]. In this study, miR-489 transfection inhibited proliferation, clone formation, migration, and invasion in prolactinoma $\mathrm{MMQ}$ and $\mathrm{GH} 3$ cell lines by directly targeting PAK3.

PAKs have been implicated in cell survival, mitosis, and transcription [19]. PAK1 and PAK4 are most frequently involved in tumorigenesis [20]. PAK3 was reported to confer a survival advantage to cancer cells by activating nicotinamide adenine dinucleotide phosphate oxidase [21]. A recent study reported that PAK3 overexpression induced cell migration and invasion in patients with thymic carcinoids accompanied with ectopic adreno-cortico-tropichormone syndrome [11]. Conversely, inhibition of PAK3 suppressed tumorigenesis and xenograft tumor growth in pancreatic cancer cells [22]. In the current study, miR-489 transfection significantly decreased PAK3 expression, while miR-489 inhibitor upregulated PAK protein levels. Luciferase reporter assays identified miR-489 directly targets PAK3, and knockdown of PAK3 inhibited prolactinoma cell proliferation, migration, and invasion. These results indicate miR-489 serves as a tumor inhibitor in pituitary prolactinoma through targeting PAK3.

This study is the first to evaluate the effect of miR-489 on pituitary prolactinoma and reveal its mechanism in vitro; however, the effects of miR489 on pituitary prolactinoma in vivo remain unclear. These results should be confirmed with in vivo experiments as well as in clinical practice. The precise mechanism by which miR-489 targets PAKs also needs in-depth study. 


\section{CONCLUSION}

MiR-489 inhibits pituitary prolactinoma by targeting PAK3, indicating that miR-489 could be developed as a potential therapy for the management of patients with pituitary prolactinoma.

\section{DECLARATIONS}

\section{Conflict of interest}

No conflict of interest is associated with this work.

\section{Contribution of authors}

We declare that this work was done by the authors named in this article and all liabilities pertaining to claims relating to the content of this article will be borne by the authors. Lie Zhang and Shuchuan Miao designed the study and supervised the data collection, Zhongxin Yang analyzed and interpreted the data, and Zongxi $\mathrm{Li}$ and Qun Zheng prepared the manuscript for publication and reviewed the draft of the manuscript. All authors read and approved the manuscript.

\section{Open Access}

This is an Open Access article that uses a funding model which does not charge readers or their institutions for access and distributed under the terms of the Creative Commons Attribution License (http://creativecommons.org/licenses/by/ 4.0) and the Budapest Open Access Initiative (http://www.budapestopenaccessinitiative.org/rea d), which permit unrestricted use, distribution, and reproduction in any medium, provided the original work is properly credited.

\section{REFERENCES}

1. Gillam MP, Molitch ME, Lombardi G, Colao A. Advances in the Treatment of Prolactinomas. Endocrine Reviews 2006; 27(5): 485-534.

2. Ciccarelli A, Daly A, Beckers A. The Epidemiology of Prolactinomas. Pituitary 2005; 8(1): 3-6.

3. Freda PU, Wardlaw SL. Diagnosis and Treatment of Pituitary Tumors. The J Clin Endocrinol Metabolism 1999; 84(11): 3859-3866.

4. He L, Hannon GJ. MicroRNAs: Small RNAs with a big role in gene regulation. Nature Reviews Genetics 2004; 5(7): 522-531.

5. Deng Z, Wei G, Qiu L, Lu H. MiR-331-5p suppresses gastric cancer cell proliferation, migration, invasion, and glycolysis via targeting PFKFB3. Trop J Pharm Res 2020; 19(11): 2265-2272.

6. Reddy KB. MicroRNA (miRNA) in cancer. Cancer Cell Int 2015; 15(1): 38-38.

7. Krichevsky AM, Gabriely G. miR-21: a small multi-faceted RNA. J Cellular Molecular Medicine 2008; 13(1): 39-53.

8. Wierinckx A, Roche M, Legraslachuer C, Trouillas J, Raverot G, Lachuer J. MicroRNAs in pituitary tumors. Molecular Cellular Endocrinol 2017; 456: 51-61.

9. Kikkawa N, Hanazawa T, Fujimura L, Nohata N, Suzuki $H$, Chazono H, Sakurai D, Horiguchi S, Okamoto Y, Seki N. miR-489 is a tumour-suppressive miRNA target PTPN11 in hypopharyngeal squamous cell carcinoma (HSCC). British J Cancer 2010; 103(6): 877-884.

10. Zhang B, Ji S, Ma Q, Lu X, Chen X. miR-489 acts as a tumor suppressor in human gastric cancer by targeting PROX1. Amer J Cancer Res 2016; 6(9): 2021.

11. Liu R, Wang $W$, Ye L, Bi Y, Fang $H$, Cui $B$, Zhou $W$, Dai $M$, Zhang $J, \quad L i \quad X$. p21-Activated kinase 3 is overexpressed in thymic neuroendocrine tumors (carcinoids) with ectopic ACTH syndrome and participates in cell migration. Endocrine 2010; 38(1): 3847.

12. Arocho A, Chen B, Ladanyi M, Pan Q. Validation of the 2DeltaDeltaCt calculation as an alternate method of data analysis for quantitative PCR of BCR-ABL P210 transcripts. Diagnostic Molecular Pathol 2006; 15(1): 56 61.

13. Lei C, Jing G, Jichao W, Xiaohui L, Fang Q, Hua G, Yazhou M, Zhang Y. MiR-137's tumor suppression on prolactinomas by targeting MITF and modulating Wnt signaling pathway. The J Clin Endocrinol Metabolism 2019; 104(12): 6391-6402.

14. Zhang $Y$, Wang Z, Chen M, Peng L, Wang $X, M a Q, M a$ F, Jiang B. MicroRNA-143 Targets MACC1 to Inhibit Cell Invasion and Migration in Colorectal cancer. Molecular Cancer 2012; 11(1): 23-23.

15. Nishikawa R, Goto Y, Kojima S, Enokida H, Chiyomaru T, Kinoshita T, Sakamoto S, Fuse M, Nakagawa M, Naya Y. Tumor-suppressive microRNA-29s inhibit cancer cell migration and invasion via targeting LAMC1 in prostate cancer. Int J Oncol 2014; 45(1): 401-410.

16. Alderman C, Sehlaoui A, Xiao Z, Yang Y. MicroRNA-15a inhibits the growth and invasiveness of malignant melanoma and directly targets on CDCA4 gene. Tumor Biol 2016; 37(10): 13941-13950.

17. Patel Y, Soni M, Awgulewitsch A, Kern MJ, Liu S, Shah $N R$, Singh UP, Chen H. Overexpression of miR-489 derails mammary hierarchy structure and inhibits HER2/neu-induced tumorigenesis. Oncogene 2019; 38(3): 445-453.

18. Li Y, Ma X, Wang Y, Li G. miR-489 inhibits proliferation, cell cycle progression and induces apoptosis of glioma cells via targeting SPIN1-mediated PI3K/AKT pathway. Biomed Pharmacother 2017; 93: 435-443.

19. Dummler B, Ohshiro K, Kumar R, Field J. Pak protein kinases and their role in cancer. Cancer Metastasis Rev 2009; 28(1): 51-63. 
20. Rane CK, Minden A. P21 activated kinase signaling in cancer. Seminars in Cancer Biol 2018; 54: 40-49.

21. Molli PR, Li DQ, Murray BW, Rayala SK, Kumar RK. PAK Signaling in Oncogenesis. Oncogene 2009; 28(28): 2545-2555.
22. Wu H, Yang M, Ding L, Chen CS, Chu P. p21-Activated kinase 3 promotes cancer stem cell phenotypes through activating the Akt-GSK3 $\beta-\beta$-catenin signaling pathway in pancreatic cancer cells. Cancer Letters 2019; 456: 1322. 